\title{
A VIABILIDADE JURÍDICA DO TESTAMENTO VITAL NO ORDENAMENTO BRASILEIRO
}

\author{
MARTINS, C. L..1; LEMOS, M. D. T. ${ }^{2}$.
}

PALAVRAS-CHAVE: Autonomia do paciente. Dignidade em final de vida. Diretiva antecipada de vontade. Testamento vital.

\begin{abstract}
RESUMO
0 presente artigo investiga o documento chamado de testamento vital, sua conceituação, utilidade e viabilidade no cenário jurídico brasileiro. Tendo em vista que, pelo viés da autonomia da vontade, o indivíduo tem o poder de decisão sobre seu corpo, questiona-se, diante da ausência de legislação específica e da aparente colisão principiológica que o permeia, se o testamento vital é juridicamente viável no Brasil. Para tanto, adota-se o método de investigação dedutivo e as técnicas de pesquisas bibliográficas, com o exame de doutrinas e da legislação, averiguação que se subdivide em três partes: conceituação e contextualização do instituto do testamento vital; elementos que o caracterizam e diferenciação com outros institutos jurídicos; análise do ordenamento e exame da viabilidade jurídica. Percebe-se que o testamento vital encontra fundamento, precipuamente, no direito à vida, que pelo viés fundamental da dignidade da pessoa humana, deverá ser protegido na acepção de vida digna, sem sofrimento e dependência. Conclui-se que o testamento vital é juridicamente viável no Brasil, pois dentro dos limites legais, realiza o direito de autodeterminação, ou seja, o poder de decisão quanto ao próprio corpo, intimamente correlacionado à dignidade da pessoa humana, fundamento do Estado Democrático de Direito.
\end{abstract}

\section{THE LEGAL FEASIBILITY OF THE LIVING WILL IN THE BRAZILIAN ORDINATION}

KEYWORDS: Patient autonomy. Dignity in critical illness. Advance directives. Living will.

\begin{abstract}
This article investigates the document called the living will, its conceptualization, usefulness and feasibility in the Brazilian legal scenario. Bearing in mind that, due to the autonomy of the will, the individual has the power to decide over his or her body, it is questioned, given the absence of specific legislation and the apparent principled collision that permeates it, whether the living will is legally viable in Brazil. Therefore, the method of deductive investigation and bibliographic research techniques are adopted, with the examination of doctrines and legislation, an investigation that is subdivided into three parts: conceptualization and contextualization of the living will institute; elements that characterize and differentiate it from other legal institutes; analysis of the order and examination of legal feasibility. It is noticed that the living will is founded, above all, on the right to life, which, due to the fundamental aspect of the dignity of the human person, should be protected in the sense of a dignified life, without suffering and dependence. It is concluded that the living will is legally viable in Brazil, as, within legal limits, it carries out the right of self-determination, that is, the power of decision regarding one's own body, closely correlated with the dignity of the human person, foundation of the Democratic State right.
\end{abstract}

Este artigo é fruto das pesquisas realizadas pela primeira autora, sob a orientação da segunda, como Trabalho de Conclusão do Curso de Direito da Universidade de Santa Cruz do Sul. Também está inserido no âmbito do projeto "O testamento vital e a garantia dos direitos de personalidade no Brasil: a viabilidade jurídico-constitucional de utilização desse instrumento como forma de manifestação da autonomia da vontade", coordenado pela segunda autora e vinculado à Universidade de Santa Cruz do Sul. Esta pesquisa recebeu o prêmio Destaque da Mostra de Extensão, Ciência e Tecnologia da UNISC, do ano de 2020.

${ }^{1}$ Acadêmica do Curso de Direito da Universidade de Santa Cruz do Sul - UNISC. E-mail: camilalmartins97@gmail.com.

2 Doutora em Direito. Professora nos cursos de Graduação e Pós-Graduação Latu Sensu da Universidade de Santa Cruz do Sul - UNISC.

Professora em Cursos Preparatórios para a OAB e carreira jurídica. Advogada. E-mail: maitedame@unisc.br. 


\section{INTRODUÇÃO}

Este artigo aborda a viabilidade do testamento vital no ordenamento jurídico brasileiro, sendo considerado um instrumento que permite a externalização prévia da vontade do indivíduo quanto aos tratamentos de saúde, para que na eventualidade da perda de capacidade para decidir, essa vontade seja conhecida e respeitada. Analisa-se a sua viabilidade, diante da sua função de materializador da autonomia da vontade, frente à ausência de legislação específica, mas amparado em fundamentos principiológicos, jurisprudenciais e outros regramentos que exacerbam o seu debate jurídico.

Tendo em vista que, pelo viés da autonomia da vontade da pessoa humana, o indivíduo tem o poder de decisão sobre seu corpo, questiona-se: é juridicamente possível que a pessoa se utilize do testamento vital como forma de diretiva antecipada de vontade, acerca de questões médicas e de saúde? A partir disso, tem-se o objetivo de discutir os elementos conceituais do testamento vital, assim como, seu objeto e a estrutura principiológica em que se insere, para ao fim, verificar sua viabilidade jurídica no ordenamento brasileiro.

0 estudo está calcado no método de investigação dedutivo, partindo do exame dos elementos que compõem o testamento vital, adentrando em sua análise jurídica e principiológica, para se chegar à conclusão geral quanto à sua viabilidade. Para tanto, adota-se as técnicas de pesquisas bibliográficas, com o exame de doutrinas, da legislação e de análise jurisprudencial.

\section{TESTAMENTO VITAL: DEBATES CONCEITUAIS}

O testamento vital surge como forma de materializar a vontade da pessoa plenamente capaz de decidir quanto ao seu próprio corpo, ante a submissão ou não a tratamentos médicos quando não mais tiver capacidade para tanto (DADALTO, 2020, p. 55). Nesse contexto, é importante, desde logo, destoar a diferença entre os testamentos tratados pelo Direito Sucessório brasileiro e o documento a ser estudado no presente trabalho.

Enquanto os testamentos civis visam produzir efeitos com a morte do autor, tendo como principal finalidade a destinação do patrimônio causa mortis. 0 testamento vital produz seus efeitos em vida, tendo em seu âmago, a autonomia da vida como principal elemento, primordialmente na tomada de decisões quanto aos cuidados, tratamentos e procedimentos que a pessoa deseja ou não se submeter (LIPPMANN, 2013, p. 17).

Nesse sentido Dadalto (2020, p. 55) também esclarece quanto às nomenclaturas usadas para tratar do testamento vital e a sua diferença aos testamentos tratados pelo direito sucessório:

[...] a nomenclatura testamento vital é fruto de errôneas e sucessivas traduções de living will. 0 erro da tradução cinge-se basicamente à incompatibilidade das características do testamento vital com a característica principal do testamento, qual seja, a produção de efeitos mortis causa, pois o conceito apresentado acima deixa claro que essa declaração surtirá efeito durante a vida do paciente.

Sendo o testamento vital um documento utilizado em diversos países ao redor do globo, em muitos desses existindo legislação própria que o regule, várias são as denominações e traduções. Entretanto, utiliza-se no Brasil a tradução do termo living will, advinda dos Estados Unidos, que é o precursor do referido instituto, conforme se verá adiante no presente trabalho (PONA, 2015, p. 42). 
É imperioso ressaltar que no testamento vital não há a solicitação de intervenção que objetive abreviar a morte, como a eutanásia, por exemplo, medida que é ilícita no direito brasileiro. 0 testamento vital é um documento escrito que possibilita a decisão, principalmente a recusa, a procedimentos e tratamentos médicos, a que não se quer ser submetido, de acordo com a sua própria vontade, seus princípios pessoais, sejam eles, morais ou religiosos (MABTUM; MARCHETTO, 2015, p. 109). Deve ser utilizado para o caso de o indivíduo encontrar-se sem condições de manifestar sua vontade. Deve-se esclarecer que este tema tem permeado as discussões doutrinárias e jurisprudenciais, tanto no âmbito do direito civil, como, também, do direito constitucional, em razão se considerar que o exercício do direito à autonomia da vontade, através do testamento vital, pode colidir com os princípios constitucionais, especialmente com o direito à vida.

Diante do que se observa, embora a mesma expressão "testamento" seja utilizada, possuem conotação diversa. Quando se trata de testamento para disposição de bens, sejam eles materiais ou virtuais, a produção de efeitos inicia após o óbito do seu titular. Já o testamento vital tem outra conotação: a produção de efeitos ainda durante a vida do disponente. 0 objetivo dessas disposições é a autorização para que profissionais da área médica possam interromper tratamentos de saúde que apenas venham a prolongar a vida do paciente, ou seja, tratamentos que não tragam a cura e apenas estendam a vida do paciente por mais tempo. Essas disposições seriam utilizadas em situações em que o indivíduo, já em estágio terminal da vida ou sem consciência, não pudesse, por si próprio, manifestar à vontade.

\footnotetext{
o testamento vital é outra espécie de diretiva antecipada de vontade por meio do qual a pessoa, de modo livre, consciente e com conhecimento, faz disposições para o seu final de vida acerca dos tratamentos, procedimentos e intervenções aos quais deseja ou não ser submetida quando não estiver em condições de decidir e declarar por si mesma (ANGELUCI, 2019, p. 53)
}

Deve-se considerar que abordar os assuntos morte e doença no âmbito familiar, ainda são tabus entre os brasileiros. Como pouco se fala sobre estes temas, no momento em que há a necessidade de decidir em nome de algum familiar, a família esbarra em certas dificuldades e incertezas na tomada da decisão sob sua responsabilidade (PONA, 2015, p. 43). Neste aspecto, se o indivíduo, podendo decidir por si, ou seja, estando em condições de manifestar sua vontade, de forma plena e esclarecida, o faz, deixando por escrito sua decisão, ameniza o sofrimento e o peso da responsabilidade da família, tornando-se do conhecimento dos demais os desejos daquele que não mais pode decidir. Esta manifestação escrita se presta tanto para doenças terminais ou crônicas, como também em situação de algum acidente que retire o estado de consciência do indivíduo (LIPPMANN, 2013, p. 22).

Maior razão há, para a utilização dos testamentos vitais, quando não houver relação de convívio estreita entre o indivíduo e sua família, já que, neste caso, em face da "ausência de contato contínuo com a família, a vontade e as preferências do paciente podem ser desconhecidas", de forma que, a família pode, em um momento avançado do estado de saúde, decidir pela retirada ou desligamento de aparelhos, contrariando o que o paciente de fato desejava (PONA, 2015, p. 47).

Importante considerar que o testamento vital pode ser utilizado tanto para a rejeição de tratamentos e procedimentos médicos, optando pela sua suspensão, como, também, pela manutenção destes (PONA, 2015, p. 43). No Brasil não há um posicionamento firmado sobre esta situação, especialmente no que diz respeito às decisões de rejeição a tratamentos, pois, se há, de um lado, o entendimento no sentido de que não é admissível 
o exercício da autonomia sobre a própria morte, de outro, existem posicionamentos doutrinários que defendem, o direito de morrer de forma digna, sem que se exija a prorrogação infindável de tratamentos de saúde (ABREU, 2013, p. 77).

Quando se trabalha com a ideia de testamento vital, entende-se como a manifestação de vontade, onde o indivíduo busca a "garantia de seu projeto individual de vida e de morte boa", sendo uma espécie de diretiva antecipada de vontade (DADALTO, 2020, p. 1), que vem a ser uma forma de autonomia da vontade. Em se tratando de autonomia privada, necessário que, desde logo, fique claro que a abordagem aqui trazida é no sentido amplo, ou seja, "capacidade do sujeito de direito de determinar seu próprio comportamento individual" (SARMENTO, 2006, p. 222). Este instrumento surge como meio de validação dos desejos do paciente, evitando as interpretações de sua vontade pelo ponto de vista de outra pessoa (BERMEJO; BELDA, 2015, p. 5).

Ademais, facilita a decisão da equipe médica que não tenha tido contato anterior com o paciente. Nesse aspecto, o Conselho Federal de Medicina, objetivando disciplinar a conduta do médico em face da inexistência de regulamentação legal acerca das disposições de vontade e, ainda, levando em conta a autonomia do paciente para decidir sobre os tratamentos aos quais quer ou não ser submetido, estabeleceu, através da Resolução 1995/2012, que o médico deve levar em consideração as diretivas antecipadas de vontade do paciente. Referida resolução não estabelece qualquer requisito a ser observado pelo médico acerca dessas diretivas antecipadas de vontade, sendo considerado como "conjunto de desejos, prévia e expressamente manifestados pelo paciente" e, ainda, que tais diretivas "prevalecerão sobre qualquer outro parecer não médico, inclusive sobre os desejos dos familiares", salvo quando "estiverem em desacordo com os preceitos ditados pelo Código de Ética Médica" (CONSELHO FEDERAL DE MEDICINA, 2012, https://sistemas.cfm.org.br/)

Assim, sem um documento anterior que reflita as vontades do paciente, em caso de emergência, o procedimento médico padrão é o de utilização do que estiver ao alcance do profissional que permita salvar o paciente. Isso se traduz, muitas vezes, no uso de técnicas que não levam em consideração o indivíduo, mas os protocolos hospitalares e médicos (MARTINEZ; LIMA, 2016, p. 114).

Importa ainda utilidade ao testamento vital no que tange a possibilidade de declarar a vontade de ser um doador de órgãos. Ressalta-se que pela legislação atual, cabe somente aos cônjuges ou parentes do falecido a autorização para a doação de órgãos (BRASIL, 2001, http://www.planalto.com.br) e, neste caso, mesmo havendo documento firmado pelo falecido, a decisão pertencerá a família. Há quem entenda possível, também, a utilização do testamento vital para fins de desejo ou não de assistência religiosa e celebrações religiosas. Lippmann (2013, p. 38), inclusive, destaca a possibilidade de se definir no testamento vital o nome do sacerdote, que gostaria de ter em sua companhia. E para a ocorrência de seu falecimento, o seu desejo por alguma cerimônia religiosa, assim como seu desejo por ser enterrado, cremado, ou que doassem o seu corpo para uma faculdade de Medicina, para fins acadêmicos. Neste sentido, contudo, importante mencionar a previsão, constante no artigo 1.881, CC, que trata dos codicilos, que prevê a possibilidade de utilização destes documentos para fins de definição do enterro do disponente (BRASIL, 2002, http://www.planalto.gov.br).

No tocante à religião, cabe ainda utilidade ao testamento vital quanto às recusas de procedimento médico por motivos religiosos. Principalmente, a sua utilização pelas testemunhas de Jeová, que se opõem à transfusão sanguínea. Não cabe discussão no presente trabalho para os motivos dessa oposição, mas sim, a sua utilização 
como exemplo do reconhecimento da autonomia dos pacientes, principalmente, através do documento do testamento vital. Há aqui, um debate constitucional que supera a proposta desta pesquisa.

\section{INSTITUTOS QUE PODEM SER INCLUÍDOS NO TESTAMENTO VITAL: DISTINÇÕES NECESSÁRIAS}

Uma vez que se tenha compreendido o conceito e a função do testamento vital, torna-se necessário trazer o debate sobre institutos e formas de terminalidade da vida, para que se defina sua viabilidade jurídica de inclusão (ou não) nos testamentos vitais. Tais distinções são necessárias, visto que muitas confusões são feitas ao tratar dessa temática. Ao realizar pesquisa sobre o tema testamento vital, muitas vezes a expressão que surge é "direito a uma morte digna", o que conduz a institutos e conceitos da bioética e do biodireito. Não se tem a pretensão, neste artigo, de se estabelecer um debate aprofundado sobre tais institutos, sua constitucionalidade ou não, mas tão somente, compreendendo-os, definir a viabilidade ou não da inclusão de cláusulas dispondo sobre a terminalidade da vida nos testamentos vitais.

Sendo a eutanásia o instituto mais conhecido, válido iniciar o estudo a partir dela. Explica Marques (2018, p. 88) que o surgimento do termo eutanásia foi "pelo Visconde inglês, Francis Bacon, que uniu duas palavras de etimologia grega; o prefixo "eu” que significa ‘boa' e o sufixo 'tanásia' que vem da palavra 'thanatos' que significa ‘morte'. Assim, o sentido literal de 'eutanásia' é 'boa morte'”. Trata-se de um ato onde um terceiro retira a vida de outrem por piedade, de forma que a motivação do autor da eutanásia é a compaixão com o outro, buscando fazer-Ihe um bem (LOPES; LIMA; SANTORO, 2018, p. 45).

Diferente da eutanásia, que abrevia a vida, a ortotanásia permite a ocorrência da morte em seu próprio tempo, sem que haja o prolongamento artificial da vida, podendo ocorrer por omissão, em que se suspende os suportes vitais, ou pela ação de retirada de equipamentos que funcionam como substitutos de órgãos ou que controlam suas funções (MABTUM; MARCHETTO, 2015, p. 70).

Em oposição a ortotanásia, existe a distanásia, que visa o prolongamento da vida, de forma desproporcional, desumano e degradante (LOPES; LIMA; SANTORO, 2018, p. 75), considerada a prática destes atos como infração ética pelos profissionais da área médica (DADALTO, 2020, p. 34).

Seguindo a lógica de comparação com o instituto anterior, surge a mistanásia como oposição à distanásia. Tem sua formação etimológica a partir da junção dos termos gregos "mys", que significa infeliz e "thanatos", morte, ou seja, seria a morte infeliz, ou morte miserável. A mistanásia é considerada, então, como uma morte miserável, que ocorre antes da hora, isso porque a pessoa não teve acesso ao atendimento do sistema de saúde, de um acompanhamento médico apropriado. Ou se teve esse atendimento, a pessoa foi negligenciada e veio a óbito (DADALTO, 2020, p. 35).

Por sua vez, o instituto do suicídio assistido é uma terminalidade da vida feita pela própria pessoa que está com uma doença grave, seja incurável ou terminal. Sendo essa a primordial diferença entre a eutanásia, pois é o próprio doente que realiza a ação final da retirada da vida. É tido como a abreviação da vida, em que a pessoa é ajudada por outrem, pode ser um médico ou não, para que lhe conceda os meios necessários para que possa, por si mesma, tirar sua vida (DADALTO, 2020, p. 33). 
Uma vez que estes institutos foram devidamente conceituados e diferenciados, importante discutir quanto à viabilidade jurídica dos institutos no sistema jurídico brasileiro, com a finalidade de entender qual ou quais desses institutos poderiam ser assunto em um testamento vital. Neste aspecto, deve-se partir do pressuposto de que quanto ao testamento vital, não há lei específica disciplinando o assunto e, com isto, o conteúdo desses documentos deve evitar contrariar entendimentos jurídicos já existentes.

Estas premissas iniciais são as bases da discussão principal do presente trabalho. Como o tema perpassa pelo exercício da autonomia privada, pela decisão, baseada em uma vontade informada do indivíduo, em submeter-se ou não a tratamentos de saúde, válidos para momentos em que não haja como o indivíduo manifestar sua vontade, necessário esclarecer que: a) a autonomia da vontade (ou autonomia privada) é um ramo do direito civil; b) essa autonomia baseia-se no exercício de um direito de liberdade, que, por sua vez, é ramo do direito constitucional, enquanto direito fundamental; c) o exercício da autonomia privada, livre e informada, possui limites no direito de terceiros e nos valores maiores da sociedade, ou seja, a liberdade é plena, desde que não fira o direito de terceiros, nem os direitos fundamentais.

Com isto, deve-se considerar que no que se refere a eutanásia, não há uma previsão constitucional expressa, mas entende-se que sua prática é vedada, tendo em vista o princípio da proteção à vida e a dignidade da pessoa humana. No âmbito penal, há a previsão do homicídio privilegiado, praticado por motivo de relevante valor moral, fazendo cessar o sofrimento que a doença causa à vítima (LOPES, 2018, p. 102-103). Sob a perspectiva ética e jurídica, pois o Código de Ética Médica proíbe a utilização da eutanásia, dizendo ser vedado ao médico abreviar a vida do paciente, ainda que a pedido deste. A legislação também proíbe a prática do suicídio assistido, considerando crime contra a vida a prestação de auxílio material para que a pessoa cometa o suicídio (PACHECO, 2014, p. 22).

Ao analisar o viés jurídico da mistanásia, Lopes, Lima e Santoro (2018, p.78) entendem que poderia configurar o crime de homicídio, mesmo não possuindo relação nenhuma com o instituto da eutanásia. $A$ mistanásia é uma forma de tratamento desumano e degradante, afrontando os direitos humanos do indivíduo, da ética que rege a atividade da medicina, assim como a bioética.

Poderia se dizer à primeira vista, que a distanásia estaria de acordo com o direito fundamental à vida, portanto seria válido ao sistema brasileiro. Porém, quando a Constituição Federal se refere ao direito à vida, o faz não exclusivamente ao direito de se permanecer vivo, de não morrer, pois parte uma perspectiva maior e mais complexa, em que se busca ao indivíduo o direito de viver dignamente (VIANA; REIS, 2016, p. 280) e não ser submetido a qualquer tratamento desumano ou degradante. Assim, o Conselho Federal de Medicina estabeleceu como infração a prática da distanásia, configurada como uma prorrogação do sofrimento do paciente terminal. A referida resolução aconselha que se pratique a ortotanásia, onde se oferece ao paciente os procedimentos paliativos disponíveis para aliviar seu sofrimento (MABTUM; MARCHETTO, 2015, p. 50).

Quanto à viabilidade da ortotanásia no Brasil, Alessi (2014, p. 171) explica que:

com relação à ortotanásia, não há infração ética nem crime em omitir o uso de meios artificiais extraordinários para manter a vida do paciente em caso de doença grave irreversível. Sobre esse tema, a resolução n. 1805/2006 do Conselho Federal de Medicina estabeleceu os critérios para a prática da ortotanásia, e essa mesma resolução foi validada pela Justiça Federal em julgamento sobre sua legalidade. 
Em 2007, o Ministério Público Federal (MPF) requereu a revogação da resolução 1805/2006 alegando abordar sobre o instituto da eutanásia, ilegal no Brasil. Requeriam ainda, que a ortotanásia fosse regulamentada pelo Congresso Nacional. Durante o processo, o MPF reconheceu a necessidade da resolução e pediu a extinção da ação. Da mesma forma procedeu o juiz, que a julgou válida. A procedência dessa resolução não foi mais contestada, porém até o momento não há nenhuma legislação tratando sobre o assunto (FERREIRA; PORTO, 2019, p. 192).

A ortotanásia permite uma compreensão da morte como um processo natural, em que o final da vida não é considerado um fracasso. Este instituto é o exemplo atual do procedimento que pauta pelo respeito à morte digna, pois possibilita uma humanização do processo de morte. Pois se durante toda a vida é preservado o respeito à dignidade, deve também o processo de morte receber o mesmo respeito (LOPES; LIMA; SANTORO 2018, p. 51).

Verifica-se, pois, que a ortotanásia constitui-se como a opção mais ponderada a ser admitida nos testamentos vitais, por não ser considerada ilegal. Volta-se a referir que não há legislação regulamentando o testamento vital e, com isto, não podem as suas disposições contrariarem as previsões e proteções legislativas já existentes. Neste aspecto, Dadalto (2020, p. 35) explica que o direito de morrer no Brasil está ligado a uma possível futura regulação do direito à ortotanásia e a manifestação de vontade do paciente através do testamento vital, em que o conteúdo a ser tratado não pode ser ilícito.

\section{FUNDAMENTO JURÍDICO-CONSTITUCIONAL DOS TESTAMENTOS VITAIS NO BRASIL}

Uma vez que foi constituída a base de entendimento sobre os testamentos vitais, é o momento de tratar da fundamentação legal e principiológica que cinge o testamento vital, para aproximar-se da resposta quanto à viabilidade desse documento no ordenamento jurídico brasileiro. Considerando que não há no Brasil qualquer regramento legal que trate sobre o gênero das medidas ou diretivas antecipadas de vontade, portanto, também não há previsão acerca da espécie testamento vital. Sem regramento específico, são os princípios e os direitos fundamentais que permitem o debate jurídico acerca da validade do testamento vital no Brasil.

O Direito não é constituído e não pode ser percebido por ramos estanques, sem ligação e interdependência. Ao contrário, deve haver uma interpretação de todos os seus ramos de acordo com a Constituição Federal, aquela que fundamenta o surgimento do Estado. Tal situação se deve ao fato de que o Direito não consegue acompanhar a evolução da sociedade. Assim, a melhor forma de fazer com que o Direito possa solucionar, da melhor forma possível, as questões existentes é fazer sua interpretação através dos ditames da Constituição. Isto porque a Constituição é capaz de evoluir com a sociedade, devido à existência de princípios, os quais possuem condições de ser aplicados em qualquer momento histórico, pois são eivados de valores éticos e morais decorrentes da própria sociedade.

Assim, é certo que o intérprete, ao aplicar o Direito, o fará de acordo com as normas existentes, mas não há como se pretender que o faça simplesmente aplicando a norma ao fato, através da subsunção, efetuando a interpretação cega da lei. Nesse sentido, se o direito privado não evolui como a sociedade, de maneira a oferecerIhe a proteção devida, porque não consegue se desenvolver de forma tão rápida, a solução é a aplicação da norma de direito privado existente, de acordo com os ditames dos princípios constitucionais e dos direitos fundamentais. 
0 processo de constitucionalização do direito privado determina a aplicação dos direitos fundamentais às relações privadas. Existem diversas teorias a explicar essa incidência (eficácia vertical, eficácia horizontal, direta, indireta, eficácia irradiante, etc). Este não é o objetivo desta discussão. Parte-se do pressuposto da incidência das normas constitucionais e, especialmente, em face da temática, dos direitos fundamentais, às relações privadas.

A Constituição, enquanto centro do ordenamento jurídico, determina que toda legislação deve a ela ser vinculada, ou seja, a Constituição irradia os seus princípios para o sistema jurídico como um todo. É através dos direitos fundamentais, que possuem uma grande força expansiva, que incidem as normas constitucionais no direito civil, que é marcado, especialmente, pelo princípio da autonomia privada. Não há como se fazer uma aplicação indiscriminada dos direitos fundamentais às relações privadas. Enquanto relações que dizem respeito ao indivíduo e que são, portanto, privada, são dotadas de certa autonomia que, contudo, não pode ser ilimitada, já que, conforme já mencionado, deve observar os direitos de terceiros e os valores maiores do próprio Estado/sociedade (UBILLOS, 2005). Desta forma, deve haver uma ponderação, uma aplicação de forma razoável dos direitos fundamentais às relações privadas. A aplicação deve ser imediata, mas considerando sempre o caso concreto, aplicando, também, os princípios da proporcionalidade e da razoabilidade, de forma a manter uma certa autonomia do indivíduo, mas sem desconsiderar os direitos fundamentais.

Os direitos de personalidade, embora estejam - alguns - elencados na legislação civil, possuem uma estreita relação com os próprios direitos fundamentais. Traz-se, nesse sentido, os exemplos dos direitos à intimidade, privacidade, imagem, que, no Código Civil estão elencados nos artigos 20 e 21, mas que também

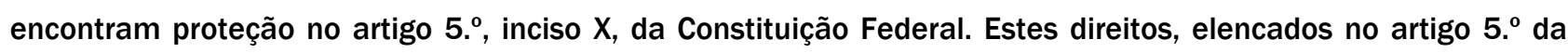
Constituição Federal, visam proteger o cidadão, garantindo-lhe uma vida digna, e são chamados de direitos fundamentais. São direitos essenciais à sobrevivência do ser humano e que, devido a sua fundamentalidade, merecem atenção e proteção especial. Estes direitos, enquanto tipo normativo, enquadram-se como princípios constitucionais, sendo aplicados a toda a ordem jurídica, inclusive a privada (SARLET, 2000).

Os princípios são o centro do sistema jurídico, sendo os valores supremos eleitos pela comunidade. Os princípios devem imperar sobre toda e qualquer apreciação do Direito, significando que valem como lei, possuindo força vinculante e determinam os fins que o Estado deve perseguir (LEAL, 2003). É possível afirmar que, no ordenamento jurídico nacional vivencia uma espécie de "Estado principiológico", o que determina a necessidade de que exista uma melhor clareza nos conceitos, para que possa auxiliar o intérprete a construir a compreensão, de forma a proporcionar um maior controle da atividade estatal.

No sistema jurídico encontra-se normas jurídicas de diferentes origens: algumas são regras e outras são princípios $^{1}$. Os direitos fundamentais podem ser chamados tanto de regras como de princípios. São normas de direitos fundamentais, porque tanto princípios quanto regras dizem o que deve ser. Pode-se dizer que os direitos fundamentais são princípios, quando se fala desses direitos como valores. Trabalha-se, aqui, neste sentido: considerando os direitos fundamentais como valores e, portanto, como princípios constitucionais. Portanto, no decorrer do trabalho, em determinados momentos fala-se em princípios e, em outras, em direitos fundamentais,

\footnotetext{
1 Não se tem a pretensão, neste artigo, de realizar o aprofundamento desta discussão. Parte-se da lógica de Robert Alexy para a distinção de princípios e regras no sistema jurídico, onde "Ios principios son normas de un grado de generalidad relativamente alto, y las reglas normas con un nivel relativamente bajo de generalidad" (ALEXY, 2002, p. 83) e, embora se saiba da existência de outros critérios, adota-se, para fins desta pesquisa, a teoria de Robert Alexy, que considera os princípios como mandamentos de otimização.
} 
mas, considerando-os sinônimos, por entender que os direitos fundamentais, neste caso, são de tamanha importância que são um valor a ser seguido e preservado.

Aqui entra a importância da presente discussão. Isto porque, os direitos de personalidade - onde está localizada a discussão acerca dos testamentos vitais - são considerados direitos fundamentais. Quando se fala em personalidade pode-se ter a compreensão enquanto capacidade de ser titular de direitos e obrigações na ordem civil (artigo 1. ${ }^{\circ}$ do Código Civil) ou, de forma mais ampla, sendo o entendimento utilizado neste trabalho, ligados às características da pessoa, seus atributos “inerentes e indispensáveis", a merecerem proteção do ordenamento jurídico (TEPEDINO, 2001, p.33). E nesse aspecto, os direitos de personalidade determinam a proteção do direito à vida, ao corpo, à honra, à imagem, vida privada e imagem - titulados, como referido, no Código Civil -, bem como outros que possam ter relação inerente e indispensável ao ser humano - daí se dizer serem direitos fundamentais.

Por fundamentais e indispensáveis, os direitos de personalidade são conhecidos pela sua generalidade, ou seja, pertencem a todos, sem segregação, bastando estar vivo possuir titularidade. Nesse sentido, alguns autores entendem que os direitos de personalidade são prévios à sua formalização jurídica, sendo assim considerados inatos. São também considerados indisponíveis, irrenunciáveis, e impenhoráveis, de forma que não se pode renunciar a esses direitos. Ponto primordial é que os direitos de personalidade são considerados absolutos, sendo dever da coletividade respeitá-Ios (TEPEDINO, 2001, p.35). As classificações dos direitos de personalidade demonstram que um dever de respeito para com o exercício do direito à vida e ao corpo, pressupõem o respeito às disposições de vontade dos testamentos vitais.

A proteção civil dos direitos de personalidade costuma dividi-los em proteção à integridade física e proteção à integridade moral. Para os fins deste trabalho, importa discutir a questão da proteção da integridade física. Em termos de Código Civil, esta proteção encontra-se nos artigos 13 a 15 e vedam disposição do próprio corpo, quando importar em diminuição permanente ou contrariar bons costumes; permite transplante ou disposição pós morte, nos termos de lei especial; e, por fim, determina que ninguém seja constrangido a submissão a tratamento médico ou intervenção cirúrgica quando importar risco de vida. Contudo, não se pode deixar de considerar o enunciado 274, das Jornadas de Direito Civil que determina que os direitos de personalidade, regulados no Código Civil, além de não terem regulamentação taxativa, relacionam-se diretamente com o princípio da dignidade da pessoa humana, previsto na Constituição Federal, no artigo $1^{\circ}$, III e, ainda e, por fim que, havendo colisão entre esses direitos, deve-se aplicar a técnica da ponderação (BRASIL, 2012a, https://www.cjf.jus.br/).

A dignidade da pessoa humana, enquanto valor fundamental da ordem jurídica brasileira e fonte dos direitos fundamentais, determina a proteção desses direitos que dela decorrem. Dessa forma, passa a ser o centro do sistema jurídico e de proteção dos direitos fundamentais. A dignidade humana, a partir de sua positivação pela Constituição Federal de 1988 passa a ser, não só um fundamento do Estado e dos direitos fundamentais, mas mais do que isso, um direito propriamente dito, já que a eficácia jurídica que Ihe foi concedida Ihe dá status de norma fundamental. Ademais, essa previsão constitucional da dignidade diz respeito ao direito a reconhecimento, respeito e proteção da dignidade, ao direito a uma existência digna e de uma morte digna.

Daí surge a discussão acerca da utilização do testamento vital, entendida como declaração de vontade, pela qual o indivíduo "estabelece disposições sobre o tipo de tratamento de saúde, ou não tratamento, que deseja no caso de se encontrar sem condições de manifestar a sua vontade" (BRASIL, 2012b, https://www.cjf.jus.br/). 
Essas disposições, ao mesmo tempo em que garantem o exercício de um direito a personalíssimo, da autonomia da vontade, também estão protegidas pelos direitos fundamentais, enquanto decorrência da dignidade da pessoa humana.

O fundamento basilar do testamento vital é a autonomia do indivíduo para decidir sobre seu próprio corpo, sobre sua integridade física, de acordo com a sua vontade. Conceitos que estão ligados às dimensões protetivas dos direitos da personalidade, que como escrevem Sengik e Rodrigues (2012, p. [2]) primam pelo bem maior do direito: o ser humano, possuidor de direitos inatos, essenciais e necessários para sua existência. E por essa razão também serão tratados no presente trabalho.

Ao definir autonomia, Cabral (2011, https://proview.thomsonreuters.com) leciona que:

\begin{abstract}
autonomia significa o poder de se autogovernar. É a faculdade de traçar suas próprias normas de conduta, sem que se seja submetido a imposições de ordem estranha. Direito de tomar decisões livremente, com liberdade, independência moral ou intelectual. É o contrário de heteronomia, que significa a sujeição a uma lei exterior ou à vontade de outrem, com ausência de autonomia. 0 heterônomo recebe do exterior as leis reguladoras da sua conduta, enquanto que o autônomo rege-se através de um regramento próprio e interno.
\end{abstract}

Evidenciada a importância da autonomia privada no contexto de autodeterminação do indivíduo e como expressão da dignidade do ser humano. Deparamo-nos com o fato de que não consta nenhuma referência expressa ao princípio na Constituição Federal de 1988. Isso não significa dizer que o constituinte tenha desprezado a matéria, pois como analisado anteriormente, se a autonomia possui papel relevante na organização do direito de um Estado, naturalmente estará presente no seu regramento fundamental, ainda que não conste expressamente (BARRETO NETO, 2013, p. [14]).

No ordenamento jurídico brasileiro o princípio da autonomia encontra respaldo implícito através do art. $5^{\circ}$, Il da Constituição Federal, pelo princípio da ampla legalidade, que estabelece que: "ninguém será obrigado a fazer ou deixar de fazer alguma coisa senão em virtude de lei” (BRASIL, 1988, http://www.planalto.com.br). Admitindose que toda pessoa maior de idade e capaz é livre para expressar suas escolhas, não sendo exigida nenhuma formalidade para tanto, exceto quando a lei expressamente exigir (DADALTO, 2020, p. 55). Pela perspectiva do paciente, o direito de autonomia Ihe traz voz, materializando seu poder de escolha. A partir deste viés, Lopes, Lima e Santoro (2018, p. 119) afirma que: “a garantia à autonomia do paciente representa respeitar sua escolha dos tratamentos aos quais quer se submeter, assim como sua recusa, especialmente quando estes foram dolorosos ou extraordinários [...]".

Quando se trabalha com a ideia de testamento vital, entende-se como a manifestação de vontade, onde o indivíduo busca a "garantia de seu projeto individual de vida e de morte boa", sendo uma espécie de diretiva antecipada de vontade (DADALTO, 2020, p. 1), que vem a ser uma forma de autonomia da vontade. Em se tratando de autonomia privada, necessário que, desde logo, fique claro que a abordagem aqui trazida é no sentido amplo, ou seja, "capacidade do sujeito de direito de determinar seu próprio comportamento individual" (SARMENTO, 2006, p. 222). Ainda se fundamenta o testamento vital como forma de expressão da dignidade da pessoa humana, como uma forma de viver com dignidade, sem sofrimento e dependência, em que se busca a vida com qualidade e não o dever de viver. 
Observa-se, ainda, que o Poder Judiciário vem reconhecendo a viabilidade jurídica dos testamentos vitais e o dever de respeito, por parte dos médicos, das decisões do paciente que se encontre em plena condição de decidir sobre sua vida e integridade física.

APELAÇÃO CÍVEL. ASSISTÊNCIA À SAÚDE. BIODIREITO. ORTOTANÁSIA. TESTAMENTO VITAL. 1. Se o paciente, com o pé esquerdo necrosado, se nega à amputação, preferindo, conforme laudo psicológico, morrer para "aliviar o sofrimento"; e, conforme laudo psiquiátrico, se encontra em pleno gozo das faculdades mentais, o Estado não pode invadir seu corpo e realizar a cirurgia mutilatória contra a sua vontade, mesmo que seja pelo motivo nobre de salvar sua vida. 2 . 0 caso se insere no denominado blodireito, na dimensão da ortotanásia, que vem a ser a morte no seu devido tempo, sem prolongar a vida por meios artificiais, ou além do que seria o processo natural. 3. 0 direito à vida garantido no art. $5^{\circ}$, caput, deve ser combinado com o princípio da dignidade da pessoa, previsto no art. $2^{\circ}$, III, ambos da CF, isto é, vida com dignidade ou razoável qualidade. A Constituição institui o direito à vida, não o dever à vida, razão pela qual não se admite que o paciente seja obrigado a se submeter a tratamento ou cirurgia, máxime quando mutilatória. Ademais, na esfera infraconstitucional, o fato de o art. 15 do $\mathrm{CC}$ proibir tratamento médico ou intervenção cirúrgica quando há risco de vida, não quer dizer que, não havendo risco, ou mesmo quando para salvar a vida, a pessoa pode ser constrangida a tal. 4. Nas circunstâncias, a fim de preservar o médico de eventual acusação de terceiros, tem-se que o paciente, pelo quanto consta nos autos, fez o denominado testamento vital, que figura na Resolução $n^{\circ} 1995 / 2012$, do Conselho Federal de Medicina. 5. Apelação desprovida.(Apelação Cível, $N^{\circ} 70054988266$, Primeira Câmara Cível, Tribunal de Justiça do RS, Relator: Irineu Mariani, Julgado em: 20-11-2013). (RIO GRANDE DO SUL, 2013, https://www.tjrs.jus.br, grifo nosso).

A decisão acima, proveniente do Tribunal de Justiça do Rio Grande do Sul, é a primeira decisão no Brasil acerca da utilização do testamento vital. Apesar da utilização do documento ter sido diferente do habitual, isto porque, o documento foi redigido pelo paciente não com a intenção de fazer a sua vontade ser conhecida pelos médicos ou familiares, mas sim, com a intenção de proteger o médico de futuro processo de omissão, já que o autor da ação/paciente se recusava a ser submetido à cirurgia de amputação do seu pé, já necrosado por lesão, mesmo ciente do alto risco de morte pela não realização da cirurgia (CHAVES; PINHEIRO; PESTANA, 2018, p. 219).

Verifica-se, pois, que embora sem a existência de uma legislação específica, o testamento vital vem sendo utilizado no Brasil. Carecendo de divulgação para que se torne um assunto de conhecimento público, precipuamente porque seu objeto inclui todos os seres humanos, não eximindo ninguém da eventualidade de encontrar-se acometido de situação clínica que retire a capacidade de decidir. 0 ano de 2020 foi marcado pela pandemia provocada pelo vírus Sars-Cov-2, causador da doença Covid-19, que se propagou pelo mundo inteiro, deixando mortos e infectados de todas as idades. São evidentes os impactos que esta pandemia provocou na vida cotidiana mundial e que são também sentidos no Direito, inclusive na produção de documentos de última vontade, como o testamento vital (CARDOSO, C.; CARDOSO, M.; NAVES NETO, 2020, p. 387).

\section{CONCLUSÃO}

A partir do exposto, obtém-se, primeiramente, que o testamento vital não pode ser confundido com o testamento civil, visto que, enquanto o primeiro trata da decisão prévia quanto a tratamentos de saúde, produzindo seus efeitos ainda em vida, o segundo preserva a decisão do indivíduo sobretudo quanto à destinação do patrimônio post mortem. Depreendeu-se que a importância do debate à validade do testamento vital recai na dificuldade da abordagem familiar quanto a temas como morte ou doença, sendo assim, por vezes a decisão tomada pelos parentes não corresponde àquela desejada pelo paciente agora incapaz de manifestar-se. 0 
testamento vital comporta a decisão prévia do indivíduo quanto aos tratamentos que efetivamente gostaria ou não de receber, trazendo certeza aos familiares do respeito à vontade do ente querido, além de trazer segurança à equipe médica frente a uma ação processual. Comportando utilidade também quanto a manifestação de ser um doador de órgãos e no que tange ao direito à religião, o testamento vital permite a recusa documentada de tratamentos médicos que não se deseja receber por motivos de crença.

Com relação ao objeto do testamento vital, realizou-se a análise individual dos institutos de terminalidade de vida estudados pela bioética, e após, averiguou-se a legalidade da utilização destes institutos em âmbito nacional. Obteve-se que os institutos da eutanásia e do suicídio assistido são ilegais ao direito brasileiro, punidos pelo Código Penal Brasileiro, levando-se em conta que estes institutos abreviam a vida do indivíduo. 0 instituto da distanásia, apesar de uma aparente legalidade, por estimular o uso de medidas extraordinárias priorizando a continuidade da vida, a distanásia se utiliza de medidas que comprometem a dignidade da pessoa, ao utilizar métodos fúteis que diminuem a autonomia da pessoa e prolongam o seu sofrimento. Por outro lado, a ortotanásia é entendida como legal ao direito brasileiro, pois neste instituto a intenção é de diminuir a dor do paciente, utilizando-se de medidas paliativas, por exemplo.

No que concerne aos fundamentos jurídicos constitucionais que cingem o testamento vital obteve-se que para uma verificação da validade jurídica do documento recai-se na necessidade da análise do direito como um todo, através das interligações interpretativas fundamentadas no texto constitucional. 0 que se verifica na possibilidade de aplicação de direitos fundamentais às relações privadas, por certo, fixamente sustentada no papel irradiador da Constituição para as demais normas e aplicações práticas do direito. Neste sentido, compreendeu-se que os direitos de personalidade comportam estreita ligação com os direitos fundamentais, principalmente no que tange o direito à dignidade da pessoa humana, logo, também promovendo o direito de uma existência digna e de uma morte digna.

0 testamento vital encontra fundamento também no direito à autonomia do indivíduo, no direito de determinação sobre o próprio corpo. Interpretação utilizada nas decisões provenientes do Poder Judiciário, que na maioria dos julgados reconhecem a validade do testamento vital, entendendo este como forma de se garantir o direito à vida a partir da interpretação do viés da dignidade da pessoa humana, portanto, não como um dever de se viver com sofrimento, mas o direito de se viver uma vida digna.

Dessarte concluiu-se pela viabilidade jurídica do testamento vital no ordenamento brasileiro. A inexistência de regramento legal específico não compromete a sua validade, tendo em vista que, por sua falta de regramento, o testamento vital restringe-se a tratar somente de objetos reconhecidamente lícitos ao direito brasileiro, fato que se verifica, ao recepcionar o instituto da ortotanásia. Ademais, o testamento vital encontra sustentação nos direitos de personalidade, e nos direitos constitucionais, primordialmente na dignidade da pessoa humana e no direito à vida. Pois se o objetivo principal do Estado Democrático é o de perfectibilização da dignidade humana, ela deve se fazer presente durante toda a vida do indivíduo, inclusive na iminência de sua morte. 


\section{REFERÊNCIAS}

ABREU, Célia Barbosa. Testamento vital entre o neoconstitucionalismo e o constitucionalismo andino. Revista Jurídica Cesumar - Mestrado, v. 13, n. 1, p. 75-95, jan./jun. 2013.

ALESSI, Alexandre. A relação médico-paciente: experiências para o médico. 1. ed. Curitiba: Orange Monkey, 2014. E-book.

ALEXY, Robert. Teoria de los derechos fundamentales. Trad. De Ernesto Garzón Valdés. Madrid: Centro de Estúdios Constitucionales, 2002.

ANGELUCI, Cleber Affonso. Considerações sobre o existir: as diretivas antecipadas de vontade e a morte digna. Revista Brasileira de Direito Civil. Belo Horizonte, v. 21, p. 39-59, jul./set. 2019.

BARROSO, Luís Roberto. Legitimidade da recusa de transfusão de sangue por testemunhas de Jeová. Revista trimestral de direito civil: RTDC. Vol. 11, n. 42, p. 49-91, abr./jun., 2010. Disponível em https://www.conjur.com.br/dl/testemunhas-jeova-sangue.pdf. Acesso em: 18 abr. 2020.

BELTRÃO, Silvio Romero. Autonomia da vontade do paciente e capacidade para consentir: uma reflexão sobre a coação irresistível. Revista de Direito Sanitário, Vol. 17, n. 2, p. 98-116, 25 out. 2016. Disponível em: http://www.revistas.usp.br/rdisan/article/view/122316/119052. Acesso em: 18 abr. 2020.

BERMEJO, José Carlos; BELDA, Rosa Maria. Testamento vital: diálogo sobre a vida, a morte e a liberdade. Tradução de Yvone Maria de C. Teixeira Silva. 1. ed. São Paulo: Edições Loyola, 2015.

BERTÉ, Roberta; XIMENES, Idelcelina Barros; SILVA, Jaquelline de Jesus. Morte Digna: A autonomia da vontade no processo de morrer. 1. ed. Teresina: Dinâmica Jurídica, 2016. E-book.

BRASIL. Conselho da Justiça Federal. Enunciado 274 da IV Jornada de Direito Civil. Coordenador: Ministro Ruy Rosado de Aguiar. Brasília: Conselho da Justiça Federal, Centro de Estudos Judiciários, 2012a. Disponível em: https://www.cjf.jus.br/cjf/corregedoria-da-justica-federal/centro-de-estudos-judiciarios-1/publicacoes1/jornadas-cej/EnunciadosAprovados-Jornadas-1345.pdf. Acesso em: 10 abr. 2020.

BRASIL. Conselho da Justiça Federal. Enunciado 528 da V Jornada de Direito Civil. Coordenador: Ministro Ruy Rosado de Aguiar. Brasília: Conselho da Justiça Federal, Centro de Estudos Judiciários, 2012b. Disponível em: https://www.cjf.jus.br/cjf/corregedoria-da-justica-federal/centro-de-estudos-judiciarios-1/publicacoes1/jornadas-cej/EnunciadosAprovados-Jornadas-1345.pdf. Acesso em: 10 abr. 2020.

BRASIL. Conselho Federal de Medicina. Resolução $n .^{\circ}$ 1995, de 09 de agosto de 2012. Dispõe sobre as diretivas antecipadas de vontade dos pacientes. Brasília, DF, 9 ago. 2012. Disponível em: https://www.legisweb.com.br/legislacao/?id=244750. Acesso em: 11 abr. 2020.

BRASIL. Lei 9.434, de 04 de fevereiro de 1997. Dispõe sobre a remoção de órgãos, tecidos e partes do corpo humano para fins de transplante e tratamento e dá outras providências. Brasília, DF, 4 fev. 1997. Disponível em: http://www.planalto.gov.br/ccivil_03/leis/I9434.htm. Acesso em: 16 abr. 2020.

BRASIL. Lei 10.406, de 10 de janeiro de 2002. Institui o Código Civil. Brasília, DF, 10 jan. 2002. Disponível em: http://www.planalto.gov.br/ccivil_03/leis/2002/I10406compilada.htm. Acesso em: 13 jan. 2021.

BRASIL. Resolução CFM n 1.995, de 31 de agosto de 2012. Dispõe sobre as diretivas antecipadas de vontade dos pacientes. Diário Oficial da União: seção 1, Brasília, DF, p. 269-270, 31 ago. 2012. Disponível em: http://www.portalmedico.org.br/resolucoes/CFM/2012/1995_2012.pdf. Acesso em: 03 set. 2020.

CHERNIJ, Carlos. Doando vida: a doação e transplante de órgãos e tecidos no Brasil. 1. ed. [S.I.: s.n.]. 2013. Ebook. 
DADALTO, Luciana. Reflexos jurídicos da Resolução CFM 1.995/12. Revista Bioética. Brasília. Vol. 21, n. 1, abr. 2013, p. 106-112. Disponível em:

http://www.scielo.br/pdf/bioet/v21n1/a12v21n1.pdf. Acesso em: 23 abr. 2002.

DADALTO, Luciana. Testamento vital. 5. ed. Indaiatuba: Foco, 2020.

DADALTO, Luciana; TUPINAMBÁS, Unai; GRECO, Dirceu Bartolomeu. Diretivas antecipadas de vontade: um modelo brasileiro. Revista Bioética. Brasília. Vol. 21, n. 3, p. 463-476, Dec. 2013 Disponível em: http://www.scielo.br/pdf/bioet/v21n3/a11v21n3.pdf. Acesso em: 18 abr. 2020.

FERREIRA, Sidnei; PORTO, Dora. Mistanásia × Qualidade de vida. Revista Bioética. Brasília. Vol. 27 n. 2, abr./jun. 2019, p. 191-195. Disponível em: http://www.scielo.br/pdf/bioet/v27n2/1983-8042-bioet-27-02-0191.pdf. Acesso em: 20 abr. 2020.

GOMES, Catarina. Maioria das testemunhas de Jeová já anda com um testamento vital na carteira. Jornal Público, Maia, 30 de jun. de 2014. Disponível em

https://www.publico.pt/2014/06/30/sociedade/noticia/maioria-das-testemunhas-de-jeova-ja-andam-com-umtestamento-vital-na-carteira-1660798. Acesso em: 19 abr. 2020.

LEAL, Mônia Clarissa Hennig. A Constituição como princípio: os limites da jurisdição constitucional brasileira. Barueri, SP: Manole, 2003.

LIPPMANN, Ernesto. Testamento vital: o direito à dignidade. 1. ed. São Paulo: Matrix, 2013. Disponível em: https://play.google.com/books/reader?id=8m7DCwAAQBAJ\&pg=GBS.PP5. Acesso em: 13 abr. 2020

LOPES, Antonio Carlos; LIMA, Carolina A. Souza; SANTORO, Luciana Freitas Eutanásia, Ortotanásia e Distanásia: aspectos médicos e jurídicos. 3. ed. São Paulo, Rio de Janeiro, Belo Horizonte: Atheneu, 2018. E-book.

MABTUM, Matheus Massaro; MARCHETTO, Patrícia Borba. 0 debate bioético e jurídico sobre as diretivas antecipadas de vontade. Editora UNESP. São Paulo; Cultura Acadêmica. São Paulo. 2015. Disponível em: https://static.scielo.org/scielobooks/qdy26/pdf/mabtum-9788579836602.pdf. Acesso em: 13 abr. 2020.

MARQUES, Gustavo Henrique Cavalcante. Direito à Morte: Uma análise da possibilidade jurídica do Direito à morte no Ordenamento Jurídico brasileiro. 1. ed. 2018. E-book.

MARQUES, Susana; CARMO, Joana; BISPO Miguel; BARREIRO Pedro; CHAGAS, Cristina; MATOS, Leopoldo. Hemorragia digestiva obscura complicada de choque em Testemunha de Jeová. Jornal Português de Gastrenterologia. Lisboa, Vol. 21, n. 4, p. 161-164, ago. 2014. Disponível em:

http://www.scielo.mec.pt/pdf/ge/v21n4/v21n4a06.pdf. Acesso em: 19 abr. 2020.

MARTINEZ, Sergio; LIMA, Adaiana. O Testamento Vital e a Relação Médico-Paciente na perspectiva da Autonomia Privada e da Dignidade da Pessoa Humana. Revista de Bioética y Derecho. Barcelona, n. 37, p. 103120. 2016. Disponível em http://scielo.isciii.es/pdf/bioetica/n37/articulo6.pdf. Acesso em: 15 abr. 2020.

MONTEIRO, Renata da Silva Fontes; SILVA JUNIOR, Aluísio Gomes, Diretivas antecipadas de vontade: percurso histórico na América Latina. Revista Bioética. Brasília. Vol.27 n. 1, jan./mar. 2019, p. 86-97. Disponível em: http://www.scielo.br/pdf/bioet/v27n1/1983-8042-bioet-27-01-0086.pdf. Acesso em: 21 abr. 2020.

PACHECO, Igor Passos Lima. Ortotanásia no Brasil: 0 direito à morte natural 1. ed. [S.I.: s.n.]. 2018. E-book.

PIMENTEL, Danielle Cortez. Eutanásia: crime contra a vida ou direito fundamental? o direito de escolher. 1. ed. Fortaleza: [s.n.], 2012. E-book.

PONA, Éverton Willian. Testamento vital e autonomia privada: Fundamentos das Diretivas Antecipadas de Vontade. 1. ed. Curitiba: Juruá Editora, 2015.

PRUDENTE, Mauro Godoy. Bioética: conceitos fundamentais. 2. ed. Porto Alegre: Editora do Autor, 2018. E-book. 
SALOMÃO, Wendell; JACOB, Cristiane Bassi. Testamento Vital - instrumento jurídico para resguardo da vontade pertinente a situações existenciais e de saúde. Colégio Registral do Rio Grande do Sul, 2015. Disponível em: https://www.colegioregistralrs.org.br/doutrinas/testamento-vital-instrumento-juridico-para-resguardo-davontade-pertinente-a-situacoes-existenciais-e-de-saude-wendell-salomao-e-cristiane-bassi-jacob/. Acesso em: 19 abr. 2020.

SARLET, Ingo Wolfgang. Direitos Fundamentais e Direito Privado: algumas considerações em torno da vinculação dos particulares aos direitos fundamentais. In: (Org.). A Constituição concretizada: construindo pontes com o público e o privado. Porto Alegre: Livraria do Advogado, 2000, p. 107-163.

SARMENTO, Daniel. Os princípios constitucionais da liberdade da autonomia privada. In: PEIXINHO, M.M.; GUERRA, I. F.; FILHO, F. N. Os princípios da Constituição de 1988. 2.ed. Rio de Janeiro: Lumen Juris, 2006, p.221-253.

TEPEDINO, Gustavo. A tutela da personalidade no ordenamento civil-constitucional brasileiro. In: . Temas de direito civil. Rio de Janeiro: Renovar, 2001.

UBILLOS, Juan Maria Bilbao. ¿Em qué medida vinculan a los particulares los derechos fundamentales? Revista da AJURIS - Associação dos juízes do Rio Grande do Sul. Porto Alegre, n. ${ }^{\circ}$ 98, p. 333-367, jun. 2005.

VIANA, Alice Pompeu; REIS Julianna Moreira. Distanásia: entre o prolongamento da vida e o direito de morrer dignamente. Revista Brasileira de Direitos e Garantias Fundamentais. Vol. 2, n. 2, p. 270-288, jul./dez. 2016. Disponível em: https://indexlaw.org/index.php/garantiasfundamentais/article/view/1643/2125. Acesso em: 20 abr. 2020. 